SCHOOL OF ACCOUNTING, FINANCE AND MANAGEMENT

The preservation of indigenous accounting systems in a subaltern community

Kelum Jayasinghe*

Essex Business School

University of Essex

Dennis Thomas

School of Management and Business

Aberystwyth University

Working Paper No. 08/09

September, 2008 


\title{
The preservation of indigenous accounting systems in a subaltern community
}

\author{
Kelum Jayasinghe* \\ Accounting, Finance Group, Essex Business School, \\ University of Essex, Wivenhoe Park, Colchester, CO4 3SQ, UK \\ and
}

\section{Dennis Thomas}

School of Management and Business, Aberystwyth University, Penglais

Campus, Aberystwyth, Ceredigion, SY23 3DD, UK.

* Correspondence:

Tel.: 44-(0)1970-622508

E-mail address: knj@aber.ac.uk

Fax: 44-(0)1970-622409

We would like to acknowledge the anonymous reviewers of Accounting, Auditing and Accountability Journal (AAAJ) and the participants at the Accounting and Subalternity Conference, Schulich School of Business, York University, Toronto, Canada, August 2007, for their valuable comments and suggestions. We also thank Dr. Mathew Tsamenyi, Birmingham Business School, University of Birmingham, for his useful feedback on earlier drafts of the paper. 


\title{
The preservation of indigenous accounting systems in a subaltern community
}

\begin{abstract}
Purpose - The paper examines how indigenous accounting practices are mobilised in the daily life of a subaltern community, and how and why the members of that community have managed to preserve such practices over time despite external pressures for change.
\end{abstract}

Methodology/approach - An ethno-methodological field study is employed to produce a text informing the ways in which people engage in social accounting practices. It uses the concepts of 'structuration theory' to understand how indigenous accounting systems are shaped by the interplay between the actions of agents and social structures.

Findings - The case study suggests that it is not literacy, social capital and trust, institutional support, or emotional imperatives that tend to 'preserve' and 'sustain' indigenous accounting systems, but the strongly prevailing patronage based political system, as mobilised into the subaltern social structure, which makes individuals unable to change. Social accounting is seen as the common language of the inhabitants in their everyday life, as sanctioned by the unique form of autonomydependency relationship shaped by patronage politics.

Originality - This is the first empirical study that focuses on how and why local 'subaltern' communities preserve their indigenous accounting practices over time. This contrasts with previous work that has focussed on the presence or absence of accounting in 'beyond work organisations'.

Research implications - The findings implicate that any form of rational transformations in indigenous accounting systems in local subaltern communities first 
requires a deconstruction analysis of any prevailing and dominant patronage political system.

Key words - Indigenous social accounting system, preservation, subaltern community, patronage political system, duality of structure, dialectic of control, systems of accountability.

Paper category - Research paper. 


\section{Introduction}

The presence and effect of accounting categories and records 'beyond work organisations', such as those found in homes and small communities, have largely remained unexplored since initial calls for accounting to be studied in such environments (Gambling, 1974; Choudhury, 1988). This paper explores how and why 'indigenous accounting practices' have been preserved in a 'subaltern' community in rural Sri Lanka despite external pressures for change. In particular, it examines how these accounting practices are mobilised in the daily life of the community and how and why members of the community have managed to preserve these practices from generation to generation.

Recently, Jacobs and Kemps (2002) studied accounting presences and absences in the daily life of three small traders in Bangladesh and concluded that the extent to which accounting is present or absent in the life of these people is explained by the level of literacy and levels of social capital. Other studies such as Gallhofer and Chew (2000), Northcott and Doolin (2000), Walker and Llewellyn (2000), Jacobs and Walker (2004), and Jayasinghe and Wickramasinghe (2007) have also provided some understanding of how accounting operates beyond work organisations. However, such studies fail to explore questions as to why and how indigenous accounting practices are preserved or transformed in such organisations. For example, how and why a particular society keeps or abandons part or all of its indigenous accounting practice, especially in the context of external pressures for rational transformations (e.g. from the state and non-government organisations (NGOs)) remains empirically unexplored. Answers to such questions require researchers to go beyond the identification of accounting presences or absences, and need the application of 'phenomenological 
understanding' of how accounting ideas are mobilised into indigenous social relations and social systems (e.g. informal credit and financing systems), which is the focus of this study.

Such an approach will open up new channels of discourse, and provides a broader understanding of 'indigenous accounting systems', as particularly featured in politically less-represented 'subaltern communities', that characterise many less developed countries (LDCs). Such, non elite, subaltern communities (Guha, 1982; Spivak, 1988) $\left.{ }^{[\mathrm{i}}\right]$ present specific characteristics, generally reflecting continuing degrees of literacy expression, both 'written' and 'oral', that have produced imperfect or incomplete literate cultures (Ong, 1982; Goody, 1987). These subalterns communities cannot speak or represent and, instead, are embedded within the dominant discourses $\left[{ }^{\mathrm{ii}}\right]$, such as those relating to economic development and poverty alleviation (Spivak, 1988; Green, 2002), and display vulnerability given the micrological texture of power relations with local and regional level elites.

This study contributes to and extends the existing work in this area, such as Choudhury (1988), Gallhofer and Chew (2000), Northcott and Doolin (2000), Walker and Llewellyn (2000), and Jacobs and Kemps (2002) in two respects. First, it examines accounting in a broader context to include both 'oral' and 'written' aspects, while previous studies in the area have narrowly focused on accounting in terms of formal record keeping, such as, debtors' records (see for instance, Jacobs and Kemps, 2002). Second, and also in contrast to previous studies, we examine why and how indigenous accounting systems have survived and been preserved over the years despite improved literacy levels and external pressures for change. 
The empirical setting of the study is an indigenous fishing community in a rural village (Kalametiya) in Sri Lanka, characterised by strong oral characteristics $\left.{ }^{[i i i}\right]$. We adopt Giddens structuration theory (Giddens 1979, 1984, 1991) as a sensitising device to understand how accounting is embedded in the daily life of community members and how indigenous accounting practices have been preserved over the years. In particular, structuration theory enables us to understand how such accounting systems are shaped by the interplay of the actions of agents on the one hand and the social structures on the other hand.

The remainder of the paper is structured as follows. In the next section we review relevant literature on the role of accounting beyond the formal work organisations, particularly in subaltern communities. Structuration theory is then presented as the theoretical framework informing our analysis. This is followed by a brief description of the research method, ahead of the presentation of case results and their discussion. The final section provides some concluding comments.

\section{Accounting beyond formal work organisations}

Accounting beyond formal work organisations, with particular regard to 'micro-level social accounting practices', remains largely unreported in the accounting literature, despite its long recognition as a valid research field (Gambling 1974; Choudhury, 1988; Hopwood, 1983, 1994; Morgan and Wilmott, 1993; Miller, 1995; Walker, 1998; Boden, 1999). By focussing on household production in national accounts in the context of macro-social accounting systems, Gambling (1974) initiated the idea of a hierarchical model of 'societal accounting' and argued for the integration of three levels of accounts in practice, namely the mini-accounts of households, micro- 
accounts and state level macro-accounts (see also Walker and Llewellyn, 2000). Hopwood $(1983,1994)$ emphasised the need for increased research on accounting and accountabilities in the every day life and cultures of people, and in support of the views Miller (1995) demanded a renewed focus on accounting as a social and institutional practice, rather than a simple rational mechanism. Extending the discussion, Morgan and Wilmott (1993) proposed a new form of accounting research to explain how individuals are affected by accounting, while Boden (1999) in her study of financial accounting and accountability among the self employed reflected the increasing need for micro-level analyses in accounting research and the importance of studying accounting practices in every day life. Walker's (1998) investigation specifically focussed on the role accounting plays in people's social life with particular regard to how the maintenance of accounting records in the private sphere contributed to masculine domination of individuals within middle class families.

The two special issues published by the Accounting, Auditing \& Accountability Journal (AAAJ) under the themes of 'accounting and indigenous peoples' (2000, Vol. 13, No 3) and 'accounting at home' (2000, Vol. 13, No. 4) promoted the idea of conducting accounting research beyond conventional organisational settings and demanded accounting researchers' attention for 'social accounting practices'. In particular, the papers published in these two issues explored the importance of undertaking accounting research in the field of household, individual, family and indigenous communities, identifying two different avenues of accounting research in the sub-field of 'social accounting'. 
Papers published in the first special issue (AAAJ, 2000, 13:3) focussed on the relationship between western accounting practice and indigenous peoples and their cultures, and investigated the impact of such accounting and accountability systems, as engineered by the state/governments, on indigenous peoples (Gallhofer and Chew, 2000; Greer and Patel, 2000). Findings indicated how western accounting has contributed to the oppression, dispossession and silencing of indigenous people's voices worldwide (Gallhofer et al., 2000), with studies of indigenous aboriginal Australians, Gibson (2000) and Greer and Patel (2000) specifically highlighting how the government, by introducing narrow notions of accounting and accountability measures for indigenous organisations and representative bodies, displaced more holistic social values in an attempt to achieve narrowly defined economic values alongside greater social equity.

The papers contained in the second special issue focussing on "accounting at home" (AAAJ, 2000, 13:4) attempted to reveal how accounting is being practiced by households and to show similarities of accounting systems prescribed for the domestic scene with those practices adopted in business (see Allen, 1977). For example, Walker and Llewellyn (2000) investigated how such accounting techniques are employed in household daily life in terms of family budgeting, household production, gender accountability, as well as matters such as divorce. Northcott and Doolin's (2000) study of home accountants in western society showed how widespread use of business jargon, computer packages, and advisory services has created a particular mass of 'home accountants' with some accounting literacy. Pahl (2000) revealed how financial arrangements of married and as-married couples reflect the economic position of their households, the relative incomes of spouses/partners, and the 
fundamental aspects of their relationship. Similarly, Komori and Humphrey (2000) explored the development of household accounting practice in post-war Japan through a review of reported experiences of the winners of the annual accounting prizes scheme organised since 1954 by the Central Council of Saving Information.

As an additional strand of related research, there is branch of literature focussing on the reasons for the 'presence' or 'absence' of written accounting beyond formal work organisations. One aspect of this sub-literature argues that absence of formal written accounting is due to practices of historically constructed pre-literate forms of accounting (Keister, 1963; Schmandt-Besserat, 1992; Baxter, 1994). This view is supported in recent studies by Jayasinghe (2006) and Jayasinghe and Wickramasinghe (2007) reporting how families and communities with less-literate cultures use customary thoughts and pre-literate 'oral accounting' calculations. Such studies suggest that accounting in such communities, homes and by individuals comprises of a set of distinctively fabricated lay conceptions rather than an act of 'writing and examination'. As an alternative emphasis, the sub-literature focuses on the relationship between literacy and accounting, treating literacy as a pre-condition for the development of accounting (Littleton, 1933; Choudhury, 1988). In particular, Choudhury (1988) argued that the presence or absence of written accounting can be interpreted as a form of pathological non-presence (e.g. lack of literacy) or as a virtue (e.g. presence of social capital and trust). In support of this argument, Jacobs and Kemp's (2002) case studies of individual traders/shop keepers in Bangladesh explored how the 'presence and absence' of written accounting at such local community level could be explained by the lack of literacy, describing how the less-literate shop keepers in their study started to keep records once they learnt to read and write. 
Furthermore, their studies showed that levels of social capital, defined as norms of reciprocity and trust, could also play an active role in understanding the absence of written accounting in traditional society (see also, Neu, 1991). Finally, a further related branch of the sub-literature argues that the presence or absence of written accounting is depended on the absence or presence of proper institutional influence, e.g. banks, tax agencies (Boden, 1999).

However, despite the focus on the presence or absence of written accounting practice beyond formal work organisations, no studies have explicitly examined why and how indigenous accounting practices have been 'preserved' or 'transformed' over the years. It has generally been found that, despite improved literacy levels and external pressures for rational transformations (e.g. by state and NGOs), individuals and local community level organisations still retain part or all of their indigenous accounting practices. However, this issue remains empirically unexplored, with the narrow focus of the social accounting sub-literature emphasising formal record keeping, such as, debtors' records (see, for instance, Jacobs and Kemps, 2002), and ignoring the issue of the preservation of indigenous accounting systems. In response, our study extends the research agenda beyond the identification of accounting presences or absences, and presents an attempt to understand phenomenologically how accounting ideas are mobilised into indigenous social relations and social systems in terms of, for example, informal credit and financing systems. In contrast to previous research in the area, we examine accounting in a broader context to include both 'oral' and 'written' and explain why and how these indigenous accounting systems have survived over the years despite external pressures for change, with a particular emphasis on subaltern communities in LDCs. 


\section{Theoretical framework: structuration theory}

In order to interpret and understand how indigenous accounting systems are shaped by the interplay of the actions of agents on the one hand and social structures on the other hand, we employ Giddens structuration theory (Giddens 1979, 1984, 1991) as a sensitising device to understand how accounting is mobilised into the every day life of community members, and how and why such accounting practices have been preserved over the years. We have been motivated by previous studies in the accounting literature that have invoked structuration theory as background (e.g. Roberts and Scapens, 1985; Capps et al., 1989; Macintosh and Scapens, 1990; Dirsmith et al., 1997; Lawrence et al., 1997; Johanson et al., 2001; Ahrens and Chapman, 2002; Buhr, 2002; Granlund, 2003; Seal et al., 2004; Coad and Cullen, 2006; Jayasinghe, 2006), while accepting that not all researchers agree on its appropriate form or utility (e.g. Boland, 1993, 1996; Burns, 2000; Dillard et al., 2004; Coad and Cullen, 2006). These studies have generally employed structuration theory to explain the parallels between conceptualisation and the practical operation of accounting systems. For instance, using Giddens' notions of 'structuration theory', as a general perspective on social life, Roberts and Scapens (1985) explained how accounting systems and systems of accountability constructs the meaning of structures, moral order and power relations in work organisations, and attempted to interpret how accounting regularises organisational functioning across time and space.

Giddens theorises a middle course between objectivism and subjectivism through his concept of 'the duality of structure' and focuses on reciprocal action of human actors and social structure. In his language, social structure is both the medium and outcome of the reproduction of practices. He explains 'systems' as the visible patterns or forms 
of interdependence between individuals and groups in organisations whereas 'structures' relate to the systems of generative rules and resources which provide the binding of time and space in social systems, even though existing outside time and space. These socially constructed structures constitute agents and social practices, and both enable and constrain the actions of human agencies. According to Giddens understanding interactions in terms of agents drawing upon and thereby reproducing particular modalities of structuration provides insights into the specific systems adopted in organisations. He identifies three 'modalities of structuration' for agential actions: interpretive schemes of communication (signification), norms for sanctioning social action (legitimation) and facilities for the exercise of power in bringing about outcomes (domination) (Giddens, 1979, p. 82)

Giddens also theorises the agents as the purposeful, knowledgeable, reflexive actors who know a great deal about the conditions and consequences of what they do in their everyday lives (Giddens, 1984, p. 281). It is through the actions and reflective monitoring of their actions that agents sustain their every day lives and social structures are constituted producing Giddens' 'duality of social structure'. As such, social structures are viewed as shaping people's actions whilst people's actions constitute, reproduce and change the social structures. Giddens' argument that structures serve as the medium of actions, as provided through memory (Giddens, 1979 , p. 5) implies a recognition of agents knowledge with regard to behaviour and responsive actions in social relations (Giddens, 1979, p. 64).

In the few accounting studies that have explicitly employed Giddens' concepts and terminology, the term 'accounting systems' in organisations is interpreted as abstract 
potential systems, whereas the systems in use are 'systems of accountability' (Roberts and Scapens, 1985; Roberts, 1990). As such, accounting systems are viewed as presenting a body of rules and resources for organisational actors which are drawn upon in the practice of accounting whilst accounting systems as whole only continue by being produced and reproduced by organisational actors drawing from and thereby reproducing 'structures' in particular contexts of interaction. In this context the word 'accountability' is interpreted in a broader sense, referring to the giving and demanding of reasons for conduct and features of daily conduct which are being shaped and maintained by accounting information (Roberts and Scapens, 1985).

These studies also present accounting as a language which provides organisation members with a set of categories (e.g. cost, profit, credit, return on investment) or system of relevance as a part of a broader 'structure of meaning' in terms of which their actions are orientated, e.g. making sense about the past, anticipating the future, planning and assessing actions (Roberts and Scapens, 1985). In addition, the study findings imply that accounting systems embody a 'moral order' in terms of a complex system of reciprocal rights and obligations of people (supported by positive and negative sanctions such as financial incentives and career prospects) to hold others to account for their actions (e.g. performance measures, budgets), and institutionalise the notion of accountability (Roberts and Scapens, 1985; Roberts, 1990; Burns and Scapens, 2000). This view emphasises how accounting practices involve the operation of power relations or a system of domination through some form of accountability (e.g. through imposing a particular framework of categories such as cost, profit, etc., upon organisational members). On the whole, structuration based studies conclude that the understanding of interactions in terms of individuals drawing upon and 
thereby reproducing particular structures of meaning, moral order and power, provides insights into the specific systems of accountability within organisations.

Accounting structures organise time by accounting periods involving, and represented by, regular reports, budgets and appraisals, together with their related practices. Accounting practices create a strict temporal order for organisations, and boundaries of systems of accountability provide for the binding of organisational time and space (Roberts and Scapens, 1985; Burns and Scapens, 2000), while the operation of 'accountability systems' produces and reproduces hierarchical, functional and divisional patterns within organisations (e.g. every employee being accountable to someone in the organisation), and structures them through time. In this perspective, researchers have argued that accounting as a language operating outside space and time can be viewed as a structure or structural property of a community of speakers that is being produced and reproduced and drawn upon by them orally in their interactions (e.g. Burns and Scapens, 2000).

While such accounting studies based on Giddens' concept of 'structuration' reflect the realities of social formation (and transformation), particularly within 'formal work organisations' from which accounting systems and systems of accountability can be conceived, we argue that these applications can equally be employed as a general perspective or paradigm with particularly relevance to understanding the social accounting calculations of subaltern communities. In this context, the elaboration and representation of social space in subaltern communities and the understanding of their underlying indigenous accounting practices, requires an examination of the anatomy 
of its articulation in terms of two interrelated elements: oral or written accounting systems, and systems of accountability.

\section{Methodology}

The method of data collection for this study involved an ethnographic approach (see Clifford and Marcus, 1986; Geertz, 1988), where the epistemological purpose is the production of a detailed text informing what is happening in a particular indigenous setting. As Boland (1993) suggested, the focal length of the researcher, in viewing structuration processes 'in close-up' or 'at a distance' may shape the ways in which these processes are observed and interpreted. This means that it is necessary to observe individuals' actions as they go about their activities, and to uncover the actors' own understandings of relevant meanings, norms and power relations. As Spivak (1988) argued "the major problem with a subaltern research project is that it requires one not only to know the consciousness and position of the subaltern but also to represent that consciousness" (p. ??). In this case, we believe that, as an interpretive method, ethnography has the ability to bring under-represented subaltern voices and consciousness into the foreground of debates on accounting and subaltern research and show the deviation of subaltern practices from the ideal and situate them historically (Guha, 1982).

The detailed research evidence for our epistemologically based case study was directly generated from prolonged contact with, and observation of, 'actors' who shared a common organisational environment. The actions, interpretations and rationalisations of each actor were observed in close-up and in repeated instances, with particular regard to their daily face-to-face contact and interaction with each 
other, in order to better and more fully appreciate the use and impact of accounting information within the whole context of their relationships. Particular attention was given to understanding different oral accounting systems assimilated within people's daily economic life and behaviour patterns. As described in the next section the chosen case study site, in rural Sri Lanka, presents a 'subaltern' village location providing us with a 'mirror face' to understand the nature of oral or written accounting systems and systems of accountability of its inhabitants.

The main data collection mode involved conducting semi-structured interviews with individuals. Each interview took approximately two hours (using the local native Sinhalese language), with the main subject matter comprising the ways in which people are engaged in the community's main economic activity of fishing and fish trading. The categories of people interviewed comprised of small-fishermen (small craft-owners and fish-workers), fish-merchants (mudalalis), specific elites (School Principal and local state fishery agent (patabandi arachchi), heads of local organisations (e.g. fishermen's cooperative society), and professionals from poverty alleviation agencies (both governmental and non-governmental). In order to capture the specific modes of accounting practices of these peoples, 28 interviews were undertaken over a six-month period. The interviews took the form of guided conversations (MacNeill, 1990), where the interviewee pursued topics and raised themes of interest within certain broad areas as prompted by the interviewer. The information generated included background details regarding respondents, their roles, tasks and relations both in family and society, accounting systems employeded to daily catch-fish sharing, informal credit, and financial management. 
Interviews took place in two stages. The first involved the interviewer becoming socialised with respondents, allowing preliminary observations regarding the latter's everyday life, and enabling further appointments to be arranged for in-depth interviewing at the second stage, during which detailed conversations took place regarding specific issues. Following the interviews, an attempt was made to compare the 'verbal data' with available documentation and reports. The purpose of this attempt was to enhance validity and reliability, with the most commonly used documents derived from detailed village resource profiles as previously collected (Abeysuriya and Jayasinghe, 2000). As part of this validation process, some participative observations were also made. As the 'outsiders' to this village, contributing to a greater understanding through physical observations of the community and its activities, in terms of overall 'harbour culture' and fishing rituals, making the ethnographic texts more graphic.

Data analysis employed the theoretical categorisation of accounting systems and systems of accountability framework in terms structures of meaning, moral order and power. Initially, this involved transcriptions to construct narratives from which was derived a single text of the story implicated with prevailing accounting systems and economic calculations therein. This was followed by textual analysis to generate interrelated stories, based on the three theoretical categories, with interpretations made with the help of theoretical insights, with particular regard to identifying the prevailing accountability systems. Finally, an iterative process was adopted - theory to data and data to theory - in order to provide a critical analysis of the empirical data (see Ahrens and Chapman, 2006). 


\section{Empirical context}

The research site of Kalametiya fishing village, is located in Hambantota district within the Southern Province of Sri Lanka and on the country's extreme southern coastline. The subaltern group within the village are largely engaged in the fishing industry, and they tend to be influenced by a few powerful elites (e.g. patabandi arachchi, fish-merchants/Mudalalis) who have control over village political economy.

Due to the potential for profit earning being constrained by two major factors - lack of capital inputs and adverse climatic conditions - Kalamatyia village, as part of the Hambantota district generally, has remained marginalised and poor. All work, living and recreation spheres of Kalametiya's inhabitants are located inside the village boundary, presenting the characteristics of a 'total institution' (Goffman, 1969) [ $\left.{ }^{\mathrm{iv}}\right]$ (see Jayasinghe and Wickramasinghe, 2007). Like many other Sinhalese villages, it is a traditional settlement with extended families and kinship relations, where the household and extended family is the main socio-economic unit, and the eldest male is the economic decision maker. The family unit promotes social unity and individual esteem, such as social status, largely derived from one's caste identity rather than individual achievements, with caste being highly determinative in the construction of social identity for the purposes of marriages, occupations, ceremonies and gatherings. The dominating caste in Kalametiya is called Karawa, which is ranked second in the system's social stratification. High poverty levels require that children give up education at a very early age, and assume the responsibilities for helping their families with many of them starting fisheing-related careers with their fathers.

Located in a natural harbour the Kalametiya village economy is almost exclusively fishing based with subaltern group fisher-folk and/or owners of small fishing craft. 
The village supplies fish to other localities and to the main fish market. A few elite fish-merchants, 'mudalalis', influence the business and monopolise fish production and distribution in manifold ways. As well as using both their own and hired mechanised craft, they hire workers for their craft, they buy the entire fish-catch from the small fishermen at lowest prices, handle the distribution network with city markets, prevent outside traders from involvement, and provide credit facilities to small fishermen to buy input materials needed for fishing trips. Elite mudalalis exclusively own the modern equipment and production technology required for multiday fishing craft, and use drift-net, long line and trawl line as their fishing gear. As such, their fish production is not affected by seasonal changes, and they are capable of middle distance operations (beyond $40 \mathrm{~km}$ ) spending 7 to 28 days at sea. While this multi-day fishing is highly capital intensive, the involvement of the owners in production is minimal and in stark contrast to small fishermen restricted to small fishing-craft with inboard or outboard engines and a limited offshore fishing range. This economic power of mudalalis is reflected in their socio-economic relations with the marginalised fishermen limited to 'patronage' relationships with mudalalis in order to obtain economic benefit.

During the last two decades, several NGOs operating under the auspices and direction of the World Bank (WB) and the Asian Development Bank (ADB) have attempted to alleviate village poverty through the modernisation of traditional fishing craft, providing finance, introducing new fishing vessels and fishing gear, developing the fishing harbour and anchorages, and managing broader coastal fisheries. These initiatives were mainly undertaken by the Fisheries Co-operative Society (FCS) formed by fisher-folk themselves, while the state, through the devices of the 
Department of Fisheries and the Department of Cooperatives, supervised its process. However, the roles performed by the FCS are politically influenced and manipulated by the elites, often holding high official posts within the FCS and also operating as state representatives of the state and national level political parties. The combined domination of regional and local elite groups and their opportunistic behaviour with regard to the fishermen group make the latter 'subalternists' in the village political economy.

\section{Accounting systems and systems of accountability in Kalametiya}

Given the empirical background, this section specifically examines the mobilisation of oral or written accounting systems and systems of accountability in the sociocultural and political economic context of Kalametiya fisher village, with regard to various aspects.

\section{Accounting period}

In Kalametiya, the concept of value does not conform to an 'accounting period', being distorted by the notion of seasonality and inconsistency of production output. The people engaged in fish production still use the bimodal pattern of rainfall in Sri Lanka

- Haraya (peak season) (monsoon period, November to April) and Warakan (off season) (monsoon period, May to October) (Amarasinghe, 2006; Jayasinghe, 2006) as the basis for financial planning and accounting at home and in their enterprise. In order to overcome the problem of seasonality of fishing operations, and to allow for year-round fishing, small-scale fishermen have attempted to mechanise their traditional craft, achieved by which simply attaching a small outboard engine. However, there is still a high dependency on traditional fishing modes, e.g. oruwa 
(outrigger canoe), which constrains sailing in poor weather conditions, reflecting an embedded and inherent caution for change because of traditions, customs, religion, or past practices.

This tendency to avoid calculative risks associated with change, militates against entrepreneurialism. The principal of the local school took the view:

"The small fishermen in this village earn good income during the peak fishing season (haraya). In fact, during the peak season there is a massive waste in fish resource because fishermen fail to sell their entire fish-catch as it often exceeds the demand. But, they do not think about preserving or processing those fish surplus to cater for the off-seasonal (warakan) market. They already have the indigenous knowledge for such enterprise. ... ... They don't need a huge capital investment and training to initiate such activities, as they are already doing it on a small scale in their homes, for their daily consumption. But they don't like to change their traditional life style. They enjoy their life during the peak-season, as they earn better income. But often they struggle when they face the off-season."

This ideology seems to be crucial in that people believe lucrative income can only be earned in the haraya period. A young school leaver who is now involved in fishing reasoned:

"I had my school education up to Ordinary Level and then I followed a Satellite Sound Reader Course at the Fisheries Training College, Tangalle. But I realised I can't find a job with those qualifications to fit with my current income that I earn from the sea. Now I am independent, and I have my own 
craft and fishing nets. I like this job (sea-fishing) and enjoy my life. Actually, I earn an average net income of Rs. 1000-1200 (per day) during the peak-season (haraya) that I would never be able to find from another job (for my paper qualifications). One day I may give up this job, but only if I find a job with better income."

The evidence suggests that the village's 'production technology' does not conform to rational economic ideals, and that traditional cultural and political ramifications have overridden and dominated any rational mobilisation of resources. The matching of prevailing 'accounting systems' with seasonal patterns of production sees people tending to base, plan and organise their family and enterprise activities on 'seasonal accounting periods'.

\section{Cost determination and profit sharing}

Similar to any other business, fish production generates various fixed overhead costs and variable costs in its total costs calculation. The former costs incurred by a fishing unit, whether or not it engages in fishing and regardless of output level, covers depreciation of craft and gear, interest payments on borrowed loan capital and imputed interest on own capital, etc. (Amarasinghe, 2006), and are mainly faced by the fish merchants as they are the owners of capital assets such as fishing crafts and fish-nets.

Those operational costs such as fuel and ice (for refrigerating catch) that do change as the level of output varies, and incurred in fishing trips, are categorised as variable costs. The fishermen borrow the money from the fish merchants to buy basic 
production inputs, i.e. engine oil, petrol, or alternatively in some cases may receive these items directly from the fish-merchants with the costs later deducted from the daily fish production revenue of the small fishermen who also hire fishing boats from the fish merchants. The evidence shows that fish merchants take a fixed rate of $50 \%$ from the daily fish-catch to cover their fixed and variable expenses. As a fishmerchant stated:

"I take $50 \%$ of the fishermen's daily fish-landing because I must recover my cost of the boat and other maintenance expenses. I take another $1 / 4$ to cover my running expenses (e.g. fuels, oil, ice-cubes)."

Among small fishermen, it was not possible to trace any personal documents showing such fixed and variable costs of daily fish production, as they avoid any formal record keeping or writing relating to their work. Although it was found that the fishmerchants keep some temporal records in the form of a 'total catch-fish revenue record', 'cash book' or 'debtor-list' in order to make sure that they collect all their debts and revenues from the small fishermen, this system is no way comparable to any system of double-entry book keeping or formal system of accounting. A fishmerchant said:

"I do not know about book keeping. But, I keep some records on the money I give to fishermen. Also, I keep some notes on my daily incomes".

In Kalametiya, the sharing of revenues/profits is based on the historically determined concept called of 'catch fish sharing system'. All key actors in the village fish-market (including small fishermen) are agreed on and apply these decision rules and subconsciously and instinctively abide by them. For example, it is a social rule that the entire fish landing is sold to the native elite mudalalis. Such rules are, on the one hand, linked to patronage relations established with the mudalalis and, on the other 
hand, mobilised in agents' practical consciousness producing particular calculable rationalities. If people break these accepted rules, the consequences are viewed as economically 'life-threatening', and the maintenance of such rules is believed to be a right and necessary practice. As a young, small scale fisherman remarked:

"I own my own fishing-craft. Every day, I used to share my daily fish-landing with my fishing partner (hawulkaraya/ganikaru). Everyday, I get 50\% share from our daily fish-catch because I have my own capital employed for the fishing trips. Then, I am getting another $1 / 2$ of the remaining $50 \%$ and my helper owns the next half. It means he receives only $1 / 4$ of the total fish-catch. We all obey this system without any negotiation because it is a system in which our predecessors invented."

In non-traditional fishing, both capital (craft) owner and labour (fish worker) receive equal shares, whereas in traditional fishing, capital receives $1 / 3$ and labour $2 / 3$ from each fishing trip. This system helps the craft owners pool the risk of loss of operational capital expenditure (e.g. depreciation or damage to craft and nets) when fishing is poor. If the catch is zero, the owner does not lose the operational capital expenditure, because it is deducted from the proceeds of the following trip before the proceeds are distributed. According to the system adopted in catch-sharing by multiday craft, operational capital expenditure on the fishing trip is deducted first from the total proceeds, and the rest is then divided between the owner (payment for capital) and the crew (payment for labour). A worker in a small multi-craft said:

"We have a common agreement of catch-fish sharing. Normally, there is minimum of 4 fish-workers engaged in those 28 days fishing trips. Each crew member receives $1 / 8$ of the total fish-catch and $50 \%$ owned by the mudalali (fish-merchant) for his boat ownership." 
In general, it is evident that the owner's share is higher for mechanised craft than for traditional craft, due to the high degree of capital intensity of such craft.

Another aspect of catch-fish sharing in Kalametiya traditionally allows people who are not involved in daily fishing trip activities to take some of the fish catch for domestic and family consumption. Neither the craft owners nor the crew object to this fish-catch distribution as they all recognise this tradition as a form of livelihood assistance. In many instances, non-active fisher-folks - often old, retired, disabled fishers or members of families whose breadwinner has died - render essential services such as removing fish from the fishing-nets (see Amarasinghe, 2006). A fish-worker stated:

"My job is removing fish, cleaning and repairing the nets. I can not do fishing because I am now too old."

According to the villagers, this form of fish-catch sharing was historically known as raula kapanawa (shaving off beard) and could be regarded as moral principles of 'the right to subsistence' and 'the norm of reciprocity' (Scott, 1976) embedded in the norms and customs of Kalametiya's fishing community.

\section{Labour costing}

Similar features were seen in relation to the 'labour costing system' operating in Kalametiya, relating to two distinct forms of labour: traditional labour mobilised by reciprocity, patronage and kinship, and the new pattern of labour associated with the advent of new deep-sea technology required for multi-day craft operations, where many of the functions performed by the traditionally experienced fish-workers (marakkalahe) have been taken over by modern equipment. The implications of this 
latter development have disturbed and distorted the otherwise strong kinship links between the marakkalahe and mechanised craft-owners and crew-workers (partners/ganikaru) that have often been pervasive, with labour having been embedded in long-term patron-client relationships. As a crew member stated:

"As a helper, I used to work in the same boat owned by our mudalali for more than five years now. I enjoy every trip and he treats me very well. Even, he helps me when I experience any financial difficulties. So, I am always loyal to him."

The close knowledge, and reliability, of one's own kinsmen traditionally ensures a convenient and rewarding reciprocity. On the one hand craft-owners obtain a dependable and guaranteed labour supply while, on the other, the system of labour recruitment guarantees employment security to the crew-workers.

Such prevailing and traditional labour contracts have created complex systems of labour valuations and costing, differing from those in modern work organisations. Labour is paid on the basis of the 'daily fish-catch (output)' and a 'fixed sharing-ratio' (1/4 or $1 / 8$ of fish-catch), instead of total working hours or standard piece rates per hour/day. However, it should be noted that with the advent of modern fishing technology, particularly the multi-day craft, the employer-employee relations have begun to undergo some faceted, if limited, changes. For example, the services of some fish-workers are now rated and paid on both time and effort bases, similar to modern work organisations, with some young fish-workers displaying a preference to work independently with no long-term commitments, an increased mobility from one employer to another as they wish, and a desire to break the traditional ideological 
barrier of their communityas reproduced by their parents in terms of the reciprocated patronage and kinship relationships with employers.

\section{Asset ownership and resource allocation}

The societal and economic relationships that characterise Kalametiya are also reflected in the unequal resource ownership capacities of fish-merchants and fishermen. Rather than being equally appropriative to all parties on a rational accounting basis (e.g. asset ownership and average income), the concentration of resource ownership amongst mudalalis confirms their transformative capacity to exercise power over fish-workers.

There is a significant disparity in the ownership of modern fishing craft and other equipment, e.g. fishing-nets. Just over a quarter (28\%) of fisher-folk own a fishingcraft with the remainder having no such ownership and are either employed as fishworkers by craft owners, or hire the craft of others on an income sharing basis (in terms of gross income not net profit), 1/4 for small craft, and 1/8 for large craft. As a poor fisherman said:

"I can not afford my own fishing-craft. Everyday I do hire one from a mudalali. I have to give $50 \%$ of my fish landing to him as the hiring cost."

Only mudalalis also have access to expensive inboard motors and multi-day craft required for off-shore and deep-sea fishing. A similar pattern is to be found in the ownership of fishing nets, where small scale fishermen only have access to pardals (tiny fishing nets which can provide a relatively small catch), while mudalalis can afford to have mardals (mass fishing nets enabling coverage of a large area of sea and access to a larger catch), which are very expensive as well as labour intensive in use. 
In conjunction with the resource ownership, there is a similar inequality with regards to the allocation of resources that flow into Kalametiya. Those resources, such as mechanised craft, fishing nets, low interest credit facilities, etc., coming from governmental organisations and NGOs are usually distributed through the FCS, where the higher and influential positions are traditionally held by the local elite (mainly fish-merchants), enabling them to take decisions regarding the nature and direction of asset allocation that favours them.

The power and influence of the mudalalis ensure that fishermen follow prescribed practices and procedures, which generally maintain patronage relations and specific arrangements such as pre-arranged fish sales (at below market prices). In all such arrangements, there are no apparent signs of formal accounting techniques (e.g. individual project appraisals or cost benefit analysis) or numbers (e.g. assets ownership or average income of fishermen) or reliable control procedures (e.g. third party authorisation, inspection or auditing) to rationalise the allocation system. For example, evidence showed that fish-workers and traditional craft owners adopt patronage relations with mudalalis to claim for newly arrived resources through the FCS. A former member of the FCS said:

"I think, our Fisheries Cooperative Society is serving for our mudalalis, not for us. They (mudalalis) always influence FCS decisions and activities. With the support of their allies every year they come to the top positions of FCS. By that way they control all the new benefits (such as fishing craft, nets and credit)". 
However, an in-depth investigation of FCS documents showed that there was some kind of record keeping and information system directed at FCS functionaries (e.g. via state agencies, NGOs), although the elite mudalalis do not allow its smoothfunctioning to obtain the desired results for third parties. Using their 'respected figure' image in the village, elite actors manipulate the externally imposed rational systems of resource allocation for their own benefit and establish tactical alliances with NGOs and regional and national level politicians to obtain legitimate access to new resources (also see Chambers, 1995; Edwards and Hume, 1995; Howell and Pearce, 2001).

\section{Budgeting, and financial management}

The absence of rational accounting practices in family and enterprise activities makes fishermen and their families in Kalametiya vulnerable to short and long-term financial problems. Additionally, their 'family budgeting and financial management practice' reflects the extent of the 'emotional' imperatives (involving a range of domestic/family/societal considerations) dominating their 'rational' imperatives (see Northcott and Doolin, 2000). Rational 'accounting categories' such as provisions, savings and net-income, which constitute the basic commercialisation of economic life (Weber, 1947) are practiced differently by these fishermen. A small grocery man remarked:

"Our fishermen earn so much money during haraya (peak-season). But spend for alcohol and enjoy with friends who do not involve with fishing. They used to buy (on credit) most of the grocery items to their family consumption from my grocery and borrow money from mudalalis, but unable to settle them in time. They have money for drinks (alcohol) but not to settle their debts. Even, 
I have to wait and catch some of them to get my money. Their families suffer a lot because of this irresponsible life style of the fishermen."

Another grocery man said:

"Our fishermen have very high expenditures during haraya, the same as the revenues. Especially, most of these fish-workers are addicted to alcohol and spend all their money to enjoy with friends. Also, they spend too much on fashions (e.g. buy bracelets, clothes). The 'savings' or 'provisions' for their future finance seem unfamiliar words to them. When they have money in hand, they travel by motor-cycles and three-wheelers, and rarely on foot. During warakan, they used to buy just single cigarettes but during haraya they buy at least a carton. But, when the warakan begins, these men put their heads down and send their women only to borrow money or buy on credit."

These two narrative quotes respectively indicate the absence and presence of 'formal accounting systems' such as budgets, records and long-term financial planning, and thus the extent of 'accounting literacy' in homes and enterprises. Observation and respondent evidence showed that national education is less valued by fish-worker families, with young children observed as leaving school-education in their early teens because of the economic problems of their family and an 'obsessive' interest in fishing jobs. The School Principal remarked:

"The school children start helping their fathers (fish-workers) in their teens (e.g. to sort and assort the fish-catch, and pull fishing-nets). Once they reach teen-age, they leave school and start their own fish-worker career at sea." 
However, and to some extent, contrary to this view, Sri Lanka's national census statistics for marine fisheries (Department of Census and Statistics, 1998) shows that a third of fishers in Hambantota province have completed their Junior Secondary School education. Although this would seem to imply that the fisher population in Kalametiya is reasonably educated (and literate) and able to contribute positively towards the management of their own fishery resources, the absence of proper planning, management and accounting for family and business finances has increased the uncertainty of individuals' every day life and allows for the introduction and prominence of 'emotions' (e.g. insecurity and guilt) into domestic financial matters (see Northcott and Doolin, 2000; Walker and Llewellyn, 2000).

\section{Informal credit and financing}

In Kalametiya, traditional fishermen's access to formal lending schemes (e.g. government schemes and NGOs loan programmes) is very low, due to their inability to offer any or appropriate collateral as demanded by lenders. Even if some schemes do operate effectively, the majority appear unsustainable because of high and subsidised costs, and high rates of default. Moreover, many formal schemes missed their target, with the benefits again captured by the elite fish-merchants. Where credit is not available, some fisher-folks have to deplete their asset base (spend savings, or sell valuables or livestock) or go without essential items, including food. A young fisherman told us:

"Our FCS and Fisheries bank offer some loans to us to buy boats and other fishing equipments. But I do not have an ability to find guarantors for the loans because nobody in the village (means elites) come forward to take that risk, as I am a poor person without any steady income from the sea. How 
could I ask such thing from someone? Even in some off-seasons which I did not have any income, I had to sell my livestock and pawn my wife's jewels. So, everybody in the village knows that only the mudalalis obtained these loans, even though it was targeted to poor fishermen."

Some fishermen also borrow from family and friends, moneylenders, shopkeepers, pawnbrokers, as well as the fish-merchants (hence confirming the dependency relationship) while remaining vulnerable to covariate risk, i.e. risk which affects everyone, such as lack of production during warakan. As an alternative, based on the 'moral' principle of 'reciprocity' and 'reciprocity-credit' (Scott, 1976), small fishermen in Kalametiya pratice the transfer of funds among themselves in order to manage short-term fish-catch and income fluctuations. This mutual insurance mechanism, providing a cushion for consumption shocks and the risk of loss of operational capital gives the otherwise vulnerable small fishermen inter-temporal flexibility in adjusting to consumption needs, especially because of the absence of insurance markets dealing with the fishermen's risk of income shortfalls (see also Amarasinghe, 2006).

Evidence shows that Kalametiya fishermen are overwhelmingly dependent on the informal credit sector, with many small craft-owners forced to be tied-up in creditdealings with mudalalis: obtaining loans on a regular basis on the promise of handing over their entire future product for a specified period of time. While such credit assists small craft owners to finance their expenditures, their observations indicated opportunistic behaviour on the part of mudalalis who reportedly often cheated them. The small scale fishermen regularly complained that the mudalalis mostly underreport the actual wholesale prices paid to them, with a hidden intention of charging a 
commission and interest on the loans granted. This 'oral calculative practice' is never openly discussed or formerly recorded in books when both parties meet. As on fisherman stated:

"I often borrow money from the mudalali to cover my daily expenses. He never asks me any guarantee. But he expects me to hand over my entire fish landings to him. I never ask how much I owe to him. I do not keep any records (or by him). But, I believe always I owe him more than I earn."

The 'handing over' of the products, as payment to mudalalis, is persistently undertaken, without considering any 'accounting information' or 'records' regarding the 'total debt value' of fishermen. As any existing transaction evidence comprises of 'oral records' and 'trust' (see Seal et al., 1997; Tomkins, 2001), the fish merchants lock fishermen into 'lifelong indebtedness' by providing loans that are repaid through fish sales at pre-arranged and unfavourable (below market) prices. The fisherman said:

"Often, I suspect that the mudalali hides the actual market prices from me. But, I can not question him, because then in the next day I can not borrow money from him again."

The evidence indicates that, prior to granting informal loans, the fish merchants conduct simple 'oral cash-flow analyses' on the fishermen's overall ability to repay the loan (e.g. on the basis of average daily fish-catch) rather than undertaking a rational investment appraisal. Sometimes, this process is linked to a successive programme of loans, starting small and increasing over time in pace with the fisherman's capacity to repay. 
In the next section we present an analysis of the case study data and provide a discussion on how indigenous accounting systems and systems of accountability are mobilised into the modalities of structuration. By doing so we attempt to answer our main research questions on why and how these indigenous accounting systems are being preserved at Kalametiya over time, despite external pressures and changing political-economic conditions.

\section{Discussion: the preservation of indigenous accounting systems}

The relationship between the social structure of Kalametiya and the agency of actors was evident in the case study. The indigenous 'social accounting systems' are mobilised into the every day life of fisher-folks and facilitate 'structuration processes'. As the actors use some social accounting analysis and techniques for their personal life and enterprise level decision-making they have reconstituted the place of accounting within the village's social structure enabling a 'duality of structure' to be observed. The fishermen's memory of past structures subconsciously influence them to preserve the ongoing structuration processes, of which the indigenous accounting systems and systems of accountability is a part of. By 'telling stories' about prior practice such as the 'catch-fish sharing system' and suggesting their reluctance to change the existing accounting and finance 'technologies' such as fixed catch-fish sharing ratio and the informal financing system, which is necessary to break with the past, some Kalametiya actors attempt to rationalise their actions in the current economic environment.

Despite the reported fact that a reasonable proportion of Kalametiya inhabitants would appear to be literate and have received institutional support from NGOs (in 
terms of training and development projects) and the state (e.g. school education), they tend to 'preserve' their indigenous social accounting systems without rational transformation. This suggests that, rather than literacy, social capital and trust (Choudhury, 1988; Jacobs and Kemp, 2002), institutional support (Boden, 1999), or emotional imperatives (Northcott and Doolin, 2000), it is the strong 'patronage political system' that tends to preserve and sustain the indigenous accounting system. As the majority of inhabitants, namely small fishermen, are vulnerable within the micrological texture of power relations with various local and regional 'elite' actors, having no influence and under-represented in mainstream discourses. In turn these 'subalterns' are forced to adopt 'patronage relationships' with the elite as their livelihood strategy, in order to access any potential benefits. In this context, the social accounting practices which were mobilised into the indigenous social systems have indirectly facilitated the social construction process of 'patronage relations'. While operating in parallel and simultaneously, the patronage political system and indigenous social accounting systems have shaped Kalametiya's social agencies.

\section{Figure 1}

In this context, the prevailing and indigenous social accounting system can be seen as representing Giddens' three 'modalities of structuration', with regards to signification, legitimation and domination within Kalametiya's social environment. The exact form and nature of this mobilisation of the social accounting system into these three modalities of structuration and their parallel and simultaneous operations with the patronage political systems can be analysed as follows. 


\section{Social accounting systems and modalities of structure at Kalametiya}

In Kalametiya accounting language has become absorbed into the every day discourse and understandings of its actors and fed into the structuration processes (Giddens, 1979). The social accounting systems such as catch-fish sharing, labour costing, budgeting, resource allocation, and informal financing have become institutionalised 'technical' systems. The 'patronised fish-market operations' have then translated into a preferred financial language (e.g. catch-fish sharing system) in order to be presented as objective and justifiable 'rituals' to its inhabitants. The non-accounting 'literate' members of the 'subaltern' fishermen group, defer to and rely on others, mainly fishmerchants, with regard to 'accounting categories and numbers' (e.g. share of profits, cost of labour), giving them a role in structuration processes. Thus, 'social accounting practices' have permeated Kalametiya's actors to share 'interpretive schemes' (a 'meaning' structure) and a 'common language' within the discourse of 'patronised fish-market operations'.

It is the issue of 'prevalent ideology', as created by the social accounting systems and systems of accountability, which leads to what is acceptable or culturally rational to the community actors, and which has motivated them to knowledgeably orientate their actions to the extant 'moral order' (legitimation structure) (Giddens, 1979, 1984; Roberts and Scapens, 1985). According to Giddens' 'structuration theory', the rules and resources of social structures both shape and constrain the actions of individuals. That is, while actors are constrained by social norms to act in a 'rational' manner, these norms also enable actors by providing a benchmark of what is considered rational and acceptable behaviour. In Kalametiya the small scale fishermen have long maintained 'patronage relations' with the powerful fish-merchants and these fish- 
merchants forcibly orientate 'legitimation structures' to the village political economy away from small fishermen's wishes, as exemplified by the fact that the fishermen are forced to sell their entire fish landing to native mudalalis and are not allowed to sell any to outsiders or the state fisheries corporation. The fish-merchants have interfered with the resource allocation mechanism and decide which assets would be allocated and to whom. Similarly, they have locked the small fishermen into lifelong indebtedness through their informal financing system.

In this context the social accounting system has facilitated the norms for sanctioning local inhabitants' actions. For instance, the fish-merchants have not kept formal records and accounting information on the loans granted to the fishermen and underreport actual wholesale prices in the market in order to charge high commissions and interest. They have also conducted oral cash flow analyses before deciding on the overall ability of fishermen to pay back the loans. In sum, by using patronage and manipulating the 'social accounting system' the elite fish-merchants have created a system of 'accountability' enabling them in effect to forcibly appropriate and collect the entire fish-production from the fishermen.

Giddens suggests that actors exercise power through their command over allocative resources (objects, goods, and other material phenomena) and authoritative resources (capability to organise and co-ordinate activities of social actors). His notion of power is not a pejorative one where actors necessarily impose their will upon others. Rather, Giddens sees power as fundamental to social interaction as a means of getting things done. The stories exemplified from the Kalametiya case study show how the powerful actors, the fish merchants, through their allocative and authoritative resources have 
structurated unequal power relations with the small scale fishermen. In response, the small fishermen have adapted their agencies to, and internalised meaning structures within, the territory of the elite mudalalis by accepting and rationalising the patronised and monopolised catch fish sharing system, the patronised labour costing system, the patronised and manipulated resource allocation, and informal credit systems. In this context indigenous social accounting systems at Kalametiya have facilitated the unequal power patterns and structurations of those patterns through time while operating in parallel with the 'patronage political system'.

\section{Social accounting systems and the dialectic of control at Kalametiya}

As Giddens (1984) stated the central focus in structuration theory of power is the 'dialectic of control', which explains power as a two-way affair between the superior and the subordinate, and a reciprocal relationship between autonomy and dependence (see also Macintosh, 1994). In all cases both parties possess some amount of power, i.e. even the subordinate can influence the activities of superiors, and the ability of one party to possess more power than the other will explain the operation of the 'domination' structure. However, in the context of Kalametiya's 'subaltern' society the influence of small-scale fishermen in the autonomy-dependency relationship seems rather negligible, even though some recent developments can be identified in their participation in, and contribution to, the 'dialectic of control'.

The authoritative and allocative resource distribution between fish-merchants and fishermen has influenced the fish-merchants' ability to monitor and control the performances of the fishermen. The fish-merchants possess the authoritative resources in the form of asset ownership, controlling positions in FCS, and the social contact 
with the regional level elite. Obviously, as the fish-merchants have a stronger influence in the village political economy through catch-fish sharing, resource allocation and informal credit systems, they tend to control the autonomy-dependency relationship with small fishermen. In response, the majority of fishermen have adapted 'patronage' as their livelihood strategy when exercising their agencies. In parallel, the social accounting systems act as a driving force facilitating the existing autonomy-dependency relationship. However, as a recent development, there appears to have been an increasing participation by the small-fishermen to the dialectic of control', as they have tended to gain greater control over their own budgets and performances than ever before as an attempted change in their indigenous social accounting practice. Their greater knowledge and expertise regarding the off-shore fishing, compared with the newly emerged asset-rich fish-merchants, the development of informal reciprocity-credit mutual insurance mechanisms against consumption shocks and risk of loss of operational capital, and changing labour relations due to the advent of modern fishing technology, have provided the small-fishermen with greater participation potential in the 'dialectic of control' in their autonomy-dependency relationship with the fish-merchants. However, this attempted change has contained certain limitations in relation to the fishermen's agency because they tend to have very little voice and representation within the dominant discourses, and asset-rich fish-merchants still dominate the autonomy-dependency relationships through their authoritative and allocative power. As such, the 'subalterns' in Kalametiya are still forced to preserve and practice traditional indigenous social accounting systems.

\section{Concluding remarks}


This paper presents an attempt to understand how and why 'indigenous accounting practices' have been preserved over generations in a 'subaltern' society, despite the consistent external pressures for change. It describes how social accounting practices are mobilised in the daily life of inhabitants and within the rural social structure. Although the issues relating to the presence or absence of accounting technology 'beyond work organisations' have already been on the research agenda of many accounting studies (e.g. Choudhury, 1988; Gallhofer and Chew, 2000; Northcott and Doolin, 2000; Walker and Llewellyn, 2000; Jacobs and Kemps, 2002; Jayasinghe and Wickramasinghe, 2007), none of these studies have explicitly treated the question of why and how such indigenous social accounting systems are being 'preserved' in such informal settings over time. This ethnographically based investigation has revealed that despite having a relatively high literacy level and considerable institutional support, such as from the state and NGOs, the indigenous people in the case study's 'subaltern' village were unable or unwilling to change their traditional social accounting practices.

In contrast to previous studies that identified issues of literacy, social capital and trust (Choudhury, 1988; Jacobs and Kemp, 2002), institutional support (Boden, 1999), or emotional imperatives (Northcott and Doolin, 2000), this study shows that the preservation and sustaining of indigenous accounting systems is explained by the strongly prevailing patronage political system mobilised in the 'subaltern' village's village social structure, making people unable to change their behaviour and practice either individually or collectively. It is observed that indigenous social accounting systems and the patronage based political system are mobilised in parallel and simultaneously into the village social structure and display and reflect modalities of 
structuration (Figure 1), with indigenous accounting techniques used to facilitate the social construction process. As specific examples, the social accounting systems relating to catch-fish sharing, resource allocation, labour costing and informal credit and finance have become patronised and manipulated to construct the patronage relationships between fish-merchants and small-fishermen (e.g. in terms of 'life long indebtness' and unequal systems of accountability).

While most 'subaltern' communities are seen as generally and inevitably reproducing historical social practices (rather than transforming them), because of their inability to influence the 'dialectic of control', this case study specifically indicates the tendency to subconsciously reproduce and sustain indigenous accounting systems which are embedded and mobilised in the social systems along with the patronage relations. A 'duality of structure' is specifically observed and interpreted in terms of 'structuration' theory, where the prevailing social accounting systems construct Giddens' modalities of structuration, in the form of interpretive schemes, norms and facilities, with the social actors (as fishermen or fish-merchants) placing the indigenous social accounting systems within the village social structure. As such, the social accounting systems and techniques have become the common language of inhabitants in their everyday life as sanctioned by patronage relationships; a unique form of autonomy-dependency relationship between the fishermen and fishmerchants.

Our investigation and evidence suggest that any rational transformations of indigenous accounting systems first require a deconstruction analysis of any prevailing patronage political systems that dominate subaltern social structures over 
time. Otherwise, indigenous accounting systems at subaltern community level will remain preserved and sustained by its inhabitants, without major transformations. Such an appreciation, combined with an appropriate methodological interpretation and approach, will expand researcher understanding of how and why indigenous accounting systems have become, and remain, culturally and politically rational practice to inhabitants in some local 'subaltern' communities, and how such accounting techniques are used differently by different users in different social settings. 
Figure 1 - Social accounting practices in a subaltern community

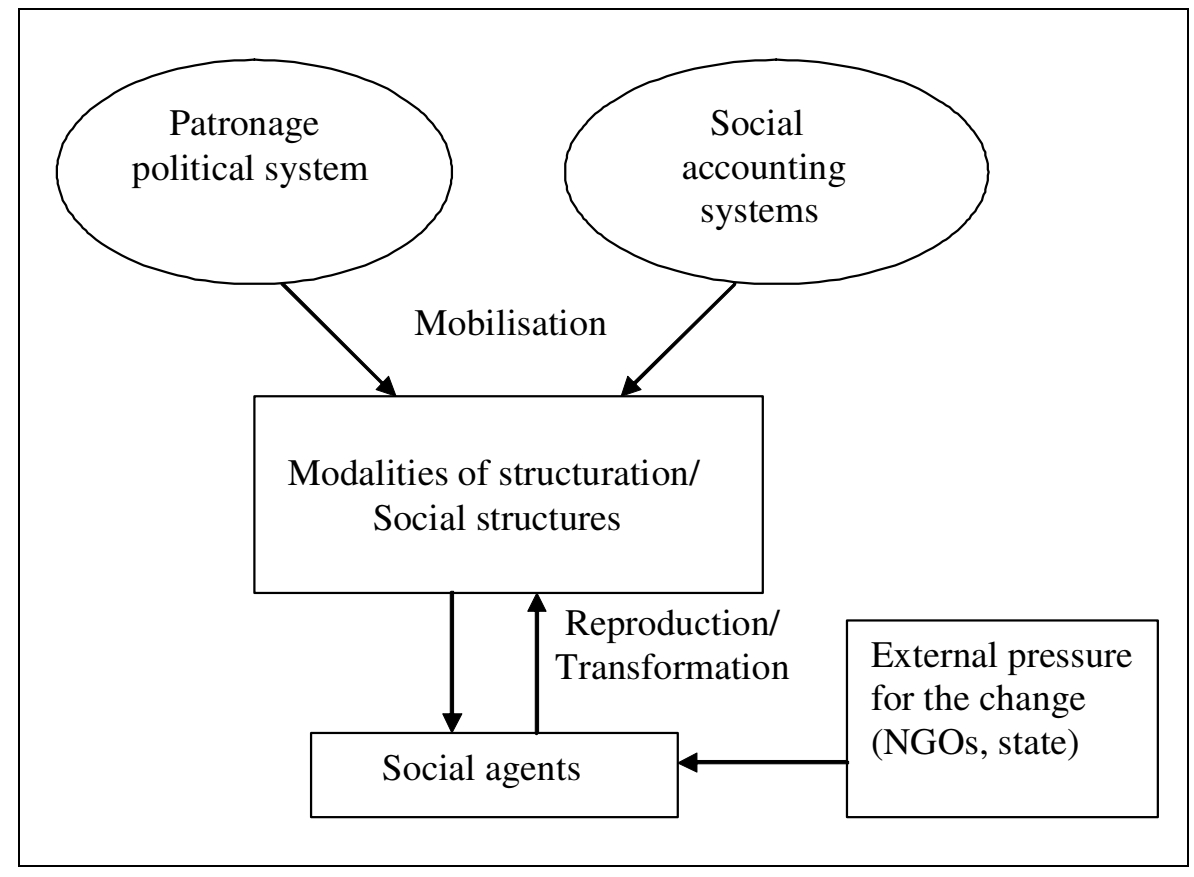

Source: Adapted from Giddens $(1979,1984)$ 


\section{References}

Abeysuriya, A. and Jayasinghe, K. (2000) Resource Profiles of Selected Villages in Hambantota District: a Report for Business Promotions, ILO-SIYB, Sri Lanka. Ahrens, T and Chapman, C.S. (2002) "The Structuration of Legitimate Performance Measures and Management: Day-to-day Contexts of Accountability in a UK Restaurant Chain”, Management Accounting Research, Vol. 13, No. 2, pp. $151-171$

Ahrens, T. and Chapman, C. S. (2006) "Doing Qualitative Field Research in Management Accounting: Positioning Data to Contribute to Theory", Accounting, Organizations and Society, Vol. 31 No. 8, pp. 819-841.

Allen, M. (1977) The Money Book - Your Money and Your Life, Pan Books, London.

Amarasinghe, O. (2001) Economic and Social Implications of Multi-day Fishing in Sri Lanka, The Coastal Communities and the Indian Ocean's Future Conference, held in Chennai, India, $9-13^{\text {th }}$ September.

Amarasinghe, O. (2006) Cooperation in a Context of Crisis: Public-Private Management of Coastal Fisheries in Sri Lanka, Working Paper Series, No. 5, Indo-Dutch Programme on Alternatives in Development (IDPAD), New Delhi.

Baxter, W. (1994) "Early Accounting: The Tally and the Checker-board" Reprinted in Parker, R. and Yamey, B. (Eds), Accounting History: Some British Contributions, Clarendon Press, Oxford.

Boden, R. (1999) "Figure it out Your Self: Financial Reporting, Accountability and the Self Employed”, Critical Perspectives on Accounting, Vol.10 No 1, pp 3764. 
Boland, R.J. (1993) "Accounting and the Interpretive Act", Accounting, Organizations and Society, Vol. 18 No. 2/3, pp. 125-146.

Boland, R.J. (1996) "Why Shared Meanings Have No Place in Structuration Theory: A Reply to Scapens and Macintosh”, Accounting, Organizations and Society, Vol. 21 No. 7/8, pp. 691-697.

Buhr, N. (2002) "A Structuration View on the Initiation of Environmental Reports", Critical Perspectives on Accounting, Vol. 13 No. 1, pp. 17-38.

Burns, J and Scapens, R.W. (2000) "Conceptualising Management Accounting Change: An Institutional Framework”, Management Accounting Research, Vol. 11, pp. 3-25.

Burns, J. (2000) “The Dynamics of Accounting Change: Interplay between New Practices, Routines, Institutions, Power and Politics, Accounting, Auditing \& Accountability Journal, Vol. 13, pp. 566-596.

Capps, T., Hopper, T., Mouritsen, J., Cooper, D. and Lowe, E. (1989) “Accounting in the Production and Reproduction of Culture", Critical Perspectives in Management Control, W.F. Chua, E. Lowe and A.G. Puxy (Eds), London, Macmillan: 217-43.

Chambers, R. (1995) "Paradigm Shifts and the Practice of Participatory Research and Development", in Nelson, N. and Wright, S. (eds.), Power and Participatory Development, Intermediate Technology Publications, UK.

Choudhury, N. (1988) "The Seeking of Accounting Where It Is Not: Towards a Theory of Non-Accounting in Organisational Settings", Accounting, Organisations and Society, Vol. 13 No. 6, pp. 549-557.

Clifford, J \& Marcus, G E (eds.) (1986) Writing Culture: The Poetics and Politics of Ethnography, University of California Press: Berkeley. 
Coad, A.F. and Cullen, J. (2006) Inter-organisational Cost Management: Towards an Evolutionary Perspective, Management Accounting Research, Vol. 17, pp. 342-369.

Cole, M. and Nicolopoulou, A. (1992) "Literacy: Intellectual consequences" in Bright, W.(Ed.), The International Encyclopaedia of Linguistics, Oxford University Press, New York, Vol. 2, pp. 343-346.

Department of Census and Statistics (1998) Census of Marine Fisheries, Colombo, Sri Lanka.

Dillard, J.F., Rigsby, J.T. and Goodman, C. (2004) "The Making and Remaking of Organisation Context: Duality and the Institutionalisation Process", Accounting, Auditing \& Accountability Journal, Vol. 17, pp. 506-542.

Dirsmith, M.W., Heian, J.B. and Covaleski, M.A. (1997) "Structure and Agency in an Institutionalised Setting: the Application and Social Transformation of Control in the Big Six”, Accounting, Organisations and Society, Vol. 22, pp. 1-27.

Edwards, M. and Hulme, D. (1995) Non-governmental Organisations - Performance and Accountability: beyond the Magic Bullet, Earthscan, with Save the Children Fund, London.

Gallhofer, S. and Chew, A. (2000) "Introduction: Accounting and Indigenous People”, Accounting, Auditing \& Accountability Journal, Vol.13 No 3, pp. 256-267.

Gallhofer, S., Gibson, K, Haslam, J. McNicholas, P. and Takiari, B. (2000) "Developing Environmental Accounting: Insights from Indigenous Cultures, Accounting, Auditing and \& Accountability Journal, Vol. 13, No. 3, pp. 381409.

Gambling, T. (1974) Societal Accounting, George Allen \& Unwin, London. 
Geertz, C. (1988) Works and Lives: The Anthropologist as Author, Stanford University Press, Stanford.

Gibson, K. (2000) “Accounting as Tool for Aboriginal Dispossession: Then and Now", Accounting, Auditing \& Accountability Journal, Vol. 13, No. 3, pp. 289-306.

Giddens, A. (1979), Central Problems in Social Theory: Action, Structure and Contradiction in Social Analysis, Macmillan, London.

Giddens, A. (1984) The Constitution of Society: Outline of the Theory of Structuration, Polity Press, Cambridge.

Giddens, A. (1991). "Structuration theory: Past, present and future", in Bryant, C.G.A. \& Jary, D., (Eds.), Giddens' Theory of Structuration: A Critical Appreciation, Routledge, London, pp. 201 - 221.

Goffman, E. (1969) The Presentation of Self in Everyday Life, Allen Lane, Penguin Press, London.

Goody, J. (1987) The Interface between the Written and the Oral (Studies in Literacy, the Family, Culture and the State), Cambridge University Press.

Granlund, M. (2003) Management Accounting Systems Integration in Corporate Mergers: A Case Study", Accounting, Auditing \& Accountability Journal, Vol. 16 No 2, pp. 208-243.

Green, M. (2002) "Gramsci Cannot Speak; Presentations and Interpretations of Gramsci's Concept of the Subaltern", Rethinking Marxism, Vol. 14 No. 3, pp. $1-24$.

Greer, S. and Patel, C. (2000) "The Issue of Australian Indigenous World-views and Accounting", Accounting, Auditing and \& Accountability Journal, Vol. 13, No. 3, pp. 307-329. 
Guha, R. (1982) "On Some Aspects of the Historiography of Colonial India", in Guha, R. Subaltern Studies I: Writings on South Asian History and Society, Oxford University Press, Delhi.

Hopwood, A. (1994) “Accounting in Everyday Life: An Introduction”, Accounting, Organisation and Society, Vol. 19 No 3, pp. 299-301.

Hopwood, A.G. (1983) "On Trying to Study Accounting in the Contexts in Which It Operates", Accounting, Organisations and Society, Vol. 8 No. 2-3, pp. 287305.

Howell, J. and Pearce, J. (2001) Civil Society and Development: a Critical exploration, Lynne Rienner Publishers, London.

Jacobs, K. and Kemp, J. (2002) "Exploring accounting presence and absence: case studies from Bangladesh", Accounting, Auditing \& Accountability Journal, Vol.15 No 2, pp. 143-161.

Jacobs, K. and Walker, S.P. (2004) "Accounting and Accountability in the Iona Community", Accounting, Auditing and Accountability Journal, Vol.17 No 3, pp. 361-381.

Jayasinghe, K. (2006) Micro-entrepreneurship in a Rural Community of Sri Lanka: A Phenomenological Study of Emotionality, Power and Calculative Practice, Unpublished $\mathrm{PhD}$ Thesis, University of Bradford.

Jayasinghe, K. and Wickramasinghe, D. (2007) "Calculative Practices in a Total Institution”, Qualitative Research in Accounting and Management, Vol. 4 No. 3, pp. 183-202.

Johanson, U., Martensson, M. and Skoog, M. (2001) "Mobilising Change through the Management Control of Intangibles", Accounting, Organisations and Society, Vol. 26 No 7/8, pp. 715-733. 
Keister, O. (1963) "Commercial Record Keeping in Ancient Mesopotamia", The Accounting Review, April, pp. 371-376.

Komori, N. and Humphrey, C. (2000) "From an Envelope to a Dream Note and a Computer - The Award Wining Experiences of Post-War Japanese Household Accounting Practices", Accounting, Auditing \& Accountability Journal, Vol. 13 No. 4, pp. 450-474.

Lawrence, S., Alam, M., Northcott, D. and Lowe, T. (1997) “Accountability Systems and Systems of Accountability: Accounting in New Zealand Health Sector Reform”, Accounting, Auditing and Accountability Journal, Vol. 10 No. 5, pp. $665-683$.

Littleton, A. (1933) Accounting Evolution to 1900, Russell \& Russell, New York, NY.

Macintosh, B.M. (1994) Management Accounting and Control Systems: An Organisational and Behavioural Approach, John Wiley \& Sons, Chichester.

Macintosh, N.B. and Scapens, R.W. (1990) "Structuration Theory in Management, Accounting”, Accounting, Organisations and Society, Vol. 15, pp. 455-477.

MacNeill, P. (1990) Research Methods, Routledge, London.

Miller, P. (1995) “Accounting as Social and Institutional Practice: An Introduction”, in Hopwood, A.G. and Miller, P. (Eds.), Accounting as Social and Institutional Practice, Cambridge University Press, Cambridge, pp. 1-39.

Morgan, G. and Willmott, H. (1993) “The 'new' Accounting Research: On Making Accounting More Visible", Accounting, Auditing \& Accountability Journal, Vol. 6, No. 4, pp. 3-36.

Neu, D. (1991) "Trust, Contracting and Prospectus Process", Accounting, Organizations and Society, Vol. 16 No. 3, pp. 243-256. 
Northcott, D. and Doolin, B. (2000) "Home Accountants: Exploring their Practices", Accounting, Auditing \& Accountability Journal, Vol.13 No 4, pp. 475-501.

Ong, W. J. (1982) Orality and literacy: The Technologizing of the Word, New York: Methuen.

Pahl, J. (2000) "Couples and their Money: Patterns of Accounting and Accounting in the Domestic Economy", Accounting, Auditing \& Accountability Journal, Vol. 13 No. 4, pp. 502-517.

Roberts, J. (1990) "Strategy and Accounting in a UK Conglomerate", Accounting, Organisations and Society, Vol. 15, pp. 107-126.

Roberts, J. and Scapens, R (1985) "Accounting Systems and Systems of Accountability: Understanding Accounting Practices in their Organizational Contexts", Accounting, Organizations and Society, Vol. 10 No. 4, pp. 443456.

Schmandt-Besserat, D. (1992) Before Writing, Volume I: From Counting to Cuneiform, University of Texas Press, Austin, TX.

Scott, J.C. (1976) The Moral Economy of the Peasant, Yale University Press, New Haven and London.

Seal, W. and Vincent-Jones, P. (1997) "Accounting and Trust in the Enabling of Long-Term Relations Accounting", Accounting, Auditing \& Accountability Journal, Vol. 10 No. 3, pp. 406-431.

Seal, W., Berry, A. and Cullen, J. (2004) "Disembedding the Supply Chain: Institutionalised Reflexivity and Inter-firm Accounting”, Accounting, Organisations and Society, Vol. 29 No. 1, pp. 73-92. 
Spivak, G.C. (1988) "Can the Subaltern Speak?" in C. Nelson and L. Grossberg

(Eds.), Marxism and the Interpretation of Culture, Urbana, University of Illinois Press.

Tomkins, C. (2001) "Interdependencies, Trust and Information in Relationships, Alliances and Networks", Accounting, Organisations and Society, Vol. 26 No. 2, pp. 161-191.

Walker, S. (1998) "How to Secure Your Husband's Esteem: Accounting and Private Patriarchy in the Middle Class Household in the Nineteenth Century", Accounting, Organisations and Society, Vol. 23, No. 5-6, pp. 485-514.

Walker, S. P. and Llewellyn, S. (2000) "Accounting at home: some interdisciplinary perspectives", Auditing \& Accountability Journal, Vol. 13 No. 4, pp. 425-449. Weber, M. (1947) The Theory of Social and Economic Organisation, Free Press, New York.

[i] Guha (1982) defines "subaltern groups" as "the people" or "nonelite." In Weberian (1947) fashion, he categorises the elite into three ideal categories: dominant foreign groups, dominant indigenous groups, and regional and local groups which act on the behalf of the other two groups. As Spivak (1988) adds, the subalterns are the people who leave little or have no traces of their existence within elite and colonial documents (or otherwise represented only as the 'Other').

[ii] As there is an overlap between 'literate' and 'oral' and the non-existence of pure non-literate oral cultures in the modern world, oral cultures does not necessarily preclude knowledge of literacy, but primarily manifests itself though the prevalence of oral performances (e.g. recitals, oratory, ritual and poetry) (Goody, 1987).

[iii] Orality is used here to mean the oral use of language through speaking and listening. Researchers disagree about how cognitive processes change across the orality/literacy continuum, but there is broad consensus for the minimal view that "literacy changes the actual and possible interactions between people and the world" (Cole and Nicolopoulou, 1992).

[iv] As Goffman (1969) observed, a total institution is an organisation, be it formal or informal, under which every aspect of life of organisational individuals is controlled and regulated by the organisational 'authorities'. These 'authorities' in the total institution would be traditions, cultures, mores, local politics, etc.. Unlike a capitalist society, a total institution integrates the spheres of the modern life, i.e. work, living and recreation, through such 'authorities' within the physically regulated boundary of the organisation (see Jayasinghe and Wickramasinghe, 2007). 